\title{
Learning EFL Online During a Pandemic: Insights into The Quality of Emergency Online Education
}

\author{
Hussein Assalahi \\ King Abdulaziz University, Jeddah, Kingdom of Saudi Arabia \\ https://orcid.org/0000-0003-4496-4285
}

\begin{abstract}
This study investigates English as a Foreign Language (EFL) learners' perceptions of the causal relationships among teaching, social, and cognitive presences, indicative of a community of inquiry in online EFL course. Their relationships to demographic variables are also explored. There has been a growing interest in using the community of inquiry framework to explore the existence of teaching, social, and cognitive presences as indicative of the quality of online educational experience. The causal relationships among the three presences and whether demographic variables such as gender and program of study predict these presences have not received considerable attention. To examine the relationships among the three presences, the Community of Inquiry (COI) survey instrument was administered to 737 learners of EFL. Factor analysis was performed, and the findings confirmed the factor structure of the COI. In addition, structural equation modelling and Chisquared automatic interaction detection (CHAID) analyses confirmed the hypothesized causal relationships among the three presences. Results revealed that teaching presence was the core factor in sustaining an online community of inquiry and gender significantly predicted perceptions of teaching presence. Implications for research on online language teaching, policy, and practice are discussed.
\end{abstract}

Keywords: EFL; community of inquiry framework; teaching presence; social presence; cognitive presence

\section{Introduction}

Online learning in higher education across the globe has witnessed a surge in demand, driven by the implications of the emergence of the COVID-19 pandemic. The International Association of Universities (IAU) Global Survey Report (Marnoni, Land \& Jensen, 2020) indicates that almost two-thirds of the participating higher education institutions $(n=424$ universities) reported a complete shift from campus-based learning to distance education; vis-à-vis 'emergency online education'. This transformation has brought about key challenges to effective teaching and learning. These issues echo growing concerns 
over disproportionate integration of pedagogical-technological approaches to promote learners' inquiry-based learning both in language research (Fotos \& Browne, 2013; Pederson; 2012) and mainstream education research (Garrison, Cleveland-Innes \& Fung, 2010; Shea \& Bidjerano, 2009). Against this backdrop, computer-assisted language learning (CALL) has witnessed a paradigm shift from cognitive to socio-cognitive approaches (Bax, 2003; Fotos \& Browne, 2013; Henry, 2019). Language acquisition is viewed as a collaborative process socially constructed and situated in particular settings (Block, 2003; Johnson, 2006; Lantolf, 2003). Despite the abundance of research in this field (Blake, 2009; Lamy \& Hampel, 2007; Lee, 2014; Pinto-Llorente \& Sánchez-Gómez, 2017), predominantly focused on learners' behaviours and attitudes (Macaro, Handley \& Walter, 2018), the dynamic relationships between teaching and learning and the social context of interaction are relatively underexplored. Informed by the community of inquiry framework (COI), the present study explores the causal relationships among teaching, social, and cognitive presences that frame the quality educational experience in an online EFL course.

\subsection{The COI framework}

The community of inquiry framework (COI) has been widely used to guide the effective conduct of online and blended learning in higher education settings (Garrison, 2017). The assumptions of COI (Figure 1) are grounded in the pursuit of higher-order learning within a community of learners engaged in critical reflection and discourse (Garrison et al., 2010, p. 32). To sustain a sense of community, COI suggests that three elements frame meaningful online experience (Garrison \& Arbaugh, 2007): 1) the teaching presence (TP), 2) the social presence (SP), and 3) the cognitive presence (CP). However, it is through the interaction and overlap among these three presences that a more profound and meaningful online experience can be generated and attained.

$\mathrm{TP}$ is the building block of a community of inquiry, enabling learners to achieve cognitive and social dimensions of learning (Garrison, Anderson \& Archer, 2000, p. 24). Teaching can be sustained in an online learning community through three components: 1) the design and organization of the course overall framework, curriculum, teaching methods, structure, interaction, and assessment of learning, 2) facilitation of interaction among students and their engagement with content, and 3) direct instruction through sharing knowledge, enhancing reflection and metacognitive skills and providing proportionate feedback. Teaching presence plays a crucial role in predicting students' satisfaction, perceived learning, and a sense of community (Garrison \& Arbaugh, 2007). The instructional design envisages the prime role of a teacher in creating meaningful experiences that go beyond providing access to online materials. It aims to "facilitate the creation of communities of learners actively and collaboratively engaged in exploring, creating meaning, and confirming understanding." (Garrison et al., 2010, p. 352) 


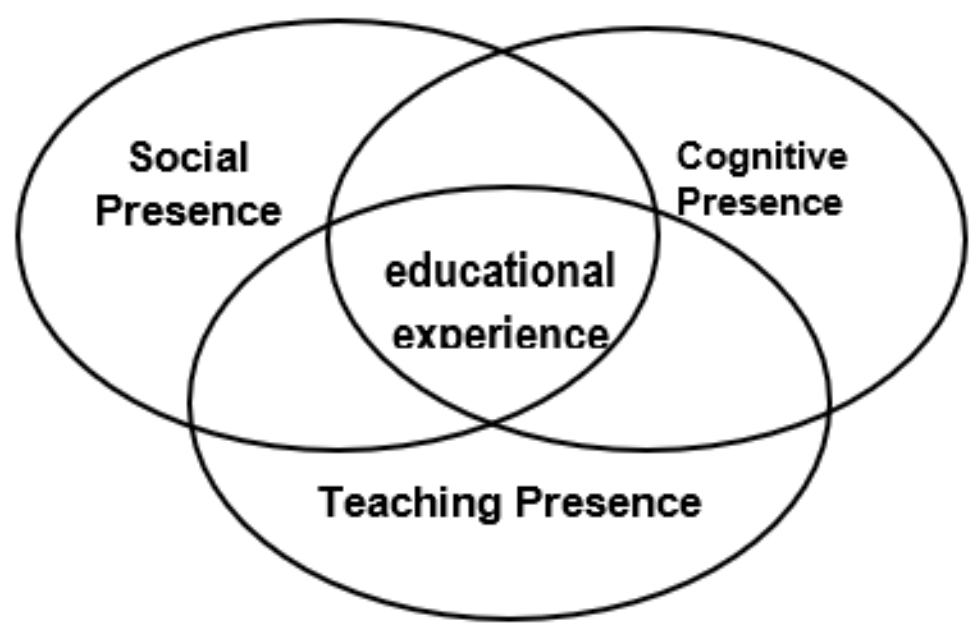

Figure 1: The COI framework (adapted from Garrison, Anderson \& Archer, 2000)

SP is defined as "the ability of learners to project themselves socially and emotionally, thereby being perceived as 'real people' in mediated communication" (Garrison \& Arbaugh, 2007, p. 159). SP consists of three elements: affective expression, open communication, and group cohesion. It enhances learners' sense of belonging through facilitating communication with the community members. This way, learners feel their views are valued and can express themselves within a trusting environment without fear of insecurity, isolation, and discouragement (Lambert \& Fisher, 2013).

$\mathrm{CP}$ describes "the extent to which learners are able to construct and confirm meaning through sustained reflection and discourse in a critical community of inquiry" (Garrison et al., 2000, p. 5). Based on collaboration and continuous reflection, communication, and critical inquiry, learners can construct new forms of knowledge. Cognitive presence in the COI framework includes four phases of inquiry: 1) the triggering event in the form of a problem of investigation, 2) exploration, where learners gather information to solve the issue under investigation, 3) integration of ideas collected individually and collaboratively to construct knowledge, and 4) resolution is attained by learners' collaborative agreement to the solution to the problem under investigation (Akyol \& Garrison, 2011).

The three presences are dynamic and interrelated to generate meaningful educational experiences in particular online settings. To point out the complexity of learning process represented by the COI framework, two lines of previous research investigating the multivariate relationship among the three presences will be outlined. A significant body of mainstream education and language research has, for the most part, focused on validating particular aspects of the COI framework (e.g., Alavi \& Taghizadeh 2013; Ke, 2010; Lambert \& Fisher, 2013). This line of research has been critiqued for contradicting the assumptions of the COI framework which emphasize that learning occurs due to the interplay among the three presences (Kozan \& Richardson, 2014a). Emerging research interest has thus addressed the need to evaluate the model as a whole through examining the 
causal relationships among the three presences (Akyol \& Garrison, 2008; Arbaugh et al., 2008; Kozan \& Richardson, 2014b; Archibald; 2010; Garrison et al., 2010; Lee, 2014; Shea \& Bidjerano, 2009). The findings of this line of research confirm that TP and SP predict CP (Garrison et al., 2010) and that SP plays a mediating role between TP and CP. Others (e.g., Shea \& Bidjerano, 2010) suggested adding the construct of learning presence to the COI framework to account for self-regulation elements such as metacognition, motivation, and behaviours. However, this contention still draws heated debates about whether adding a fourth element to the COI framework is needed since 'co-regulation' is an integral element of the three presences (Akyol \& Garrison, 2011; Garrison, 2017). Finally, the literature surveyed located only one study conducted in the Saudi context, which investigated the correlation of the COI framework to students' satisfaction with the online program at a Saudi University (Alaulamie, 2014). It also validated the hypothesized relationship among COI presences.

While there is a lack of research examining the causal relationships among the three presences in online language learning environments, a growing body of language research has examined the impact of the COI on learning behaviours, students' achievement, and satisfaction. Three studies that illustrate this effect will be examined. Goda \& Yamada (2013) found that TP and CP were correlated with students' satisfaction in asynchronous online discussions. A higher number of discussion comments significantly correlated with teaching and social presences, and higher students' satisfaction correlated strongly with TP, SP, and CP. Asynchronous discussions in online communities of inquiry are effective learning tools because learners can "apply and practice what they have learned" and "express their ideas and communicate with others" (Goda \& Yamada, 2013, p. 296). Similar findings were reported by Asoodar et al. (2014), who found out that blogs, besides other applications that enhance collaboration and communication, influenced students' learning satisfaction and academic performance. They posit that the COI framework intervention enabled students to create and engage in a community of inquiry with a strong sense of SP, which positively affected the CP. Students with a strong sense of community also showed better academic performance. Their collaboration in online writing blogs helped them co-construct knowledge with the support of peers and learning materials. Olesova et al. (2011) found that teachers' audio feedback was perceived by EFL and ESL students to be better than text feedback. Still, no significant differences in preferences were found between the two groups. However, the teaching presence as an audio-mode feedback was perceived to be more effective for ESL students. The written feedback was more effective in enhancing both groups' cognitive presence and satisfaction levels. The different preference was assigned to EFL students' inclination towards rereading teachers' comments, while ESL students preferred reflecting on teachers' pronunciation and enhancing comprehension.

Finally, interest in examining the impact of learners' characteristics such as gender has grown considerably due to gender-based achievement gaps in online learning environments both in the Saudi context and internationally (Adamus, Kerres, Getto \& Engelhardt, 2009; Al Lily, 2011). These variables have been reported to influence learners' satisfaction, sense of community and engagement, retention, 
and educational effectiveness (Al lHassan \& Shukri, 2017; Garrison et al., 2010; Rovai \& Baker, 2005; Shea \& Bidjerano; 2010). Research also indicates a direct effect of gender on teaching presence (Shea \& Bidjerano, 2010; Garrison et al., 2010). Evidence suggests that women have greater motivation in online English language learning environments than men (Wang \& Zhan, 2020). Al lHassan and Shukri (2017) reported similar findings and indicated that Saudi female students were highly satisfied with the learning management system's resources' richness. However, women's persistence in online programs is hampered by "multiple responsibilities, insufficient interaction with faculty, technology, and coursework" (Müller, 2008, p. 1). The program of study is another variable of interest in this research study due to its potential to influence the relationships among the COI presences (Garrison et al., 2010). The studies conducted in EFL contexts provide significant insights, especially regarding the impact of the COI framework in designing the course content on perceptions of the presences. However, the causal relationships among these presences are not fully understood.

This study set out to address these limitations and answer the following research questions:

(1) Do teaching, social and cognitive presences explored in an online EFL course result in coherent factor structure of COI?

(2) Do the three presences correlate by the COI framework?

(3) Do gender and program of study predict each of the three presences?

(4) What item-level responses of the teaching and social presences reflect their significance in predicting cognitive presence?

\section{Methods}

The purpose of this quantitative research study was to examine EFL learners' perceptions of the relationships among the three presences in learning English as a foreign language online. The causal research design was adopted to investigate the causal relationships among the COI factors (Shea \& Bidjerano, 2009), in different settings (Garrison et al., 2010).

\subsection{Data collection}

An adapted version of the Community of Inquiry Framework Survey (Arbaugh et al., 2008) was employed as the data collection instrument (Appendix.1). Seminal work in the field (e.g., Garrison et al., 2010; Shea \& Bidjerano, 2009) suggests that the COI survey is a valid and reliable instrument for investigating the interaction and overlap among $\mathrm{TP}, \mathrm{SP}$ and $\mathrm{CP}$ in online learning environments to generate meaningful learning experience. The 34-item questionnaire examined the three presences; 13 questions examined TP, 9 questions examined SP, and 12 questions examined $\mathrm{CP}$. The responses were elicited by the 5 -point Likert scale ( $1=$ strongly agree, 2 = disagree, $3=$ neutral, $4=$ agree, $5=$ strongly disagree). The survey also obtained demographic information about gender and program of study.

\subsection{Sampling}

A sample of 737 was randomly selected from a list of EFL foundation year students. The sample represents students from two campuses (male and female campuses). Students study the foundation program through Blackboard as the 
main learning management system and also go through the same assessment procedures. The programs' instructors receive the same professional development support. Female students $(n=396)$ represented $53 \%$ of the sample while male students $(n=341)$ accounted for $46.3 \% .70 \%$ of these students $(n=516)$ were general English track students, and 30\% ( $n=221)$ were academic English track students. An accessible URL link to the electronic version of the COI-Survey instrument was emailed to all participants. The informed consent form was included in the questionnaire, which identified information about the study and the ethical guidelines of investigation.

\subsection{Piloting}

The COI survey instrument, which has been widely used, validated, and translated in different languages, was first translated in Arabic to check for conceptual and cultural equivalence of the COI. This process was achieved through forward, backward, and expert panel translation approaches. The researcher translated the COI items into Arabic, and then two TESOL Ph.D. holders were convened to identify and resolve problematic issues in the translated COI. Discrepancies between the two versions were identified, and then alternative expressions were suggested and included in the final version of the survey. It was then piloted with a class of 35 EFL students to check for linguistic, conceptual, and cultural ambiguities and all respondents reported no issues or complaints. The final version of the questionnaire was emailed to all foundation year students at the end of the English Language course (module 3) in the second semester at a university in Saudi Arabia.

\subsection{The English Language course}

The population of this research study were undergraduate students enrolled in a preparatory year program to study the English language as an admission requirement prior to pursuing undergraduate degree programs. Students are admitted into two programs based on their major of interest. These are academic English for the sciences track and general English for the art track. For each track, students are assigned into four language levels based on placement test results. There is a minimum linguistic achievement requirement for each level, which is benchmarked with the corresponding European Framework of Reference (CEFR) level. The course design follows a modular approach, and each module lasts for eight weeks. The instruction is usually conducted face-to-face with an online written component (via Blackboard) for assessment purposes. However, due to Coronavirus (COVID-19) pandemic, learning shifted to fully online education through learning management systems (Blackboard). This transformation has entailed a change in assessment policy for both tracks. Thus, there are three types of assessment that make up the overall assessment for each module. These comprise ongoing module work and final computer-based test (CBT). The ongoing module work includes written assignments such as daily activities and discussion forums. Each student is required to complete and submit these assignments through Blackboard.

\subsection{Data preparation}

The data were first checked for reliability and validity of instrument scores, missing values, univariate and multivariate outliers, and assumptions of 
normality. The descriptive statistics obtained through the SPSS (Table 1) indicate that no missing values were observed for all the variables.

Table 1. Descriptive statistics

\begin{tabular}{lllc}
\hline & $\mathbf{N}$ & Mean & Std. Deviation \\
\hline Teaching Presence & 737 & 3.90 & 0.98 \\
\hline Social Presence & 737 & 3.76 & 0.99 \\
\hline Cognitive Presence & 737 & 3.68 & 0.99 \\
\hline Valid N (listwise) & 737 & & \\
\hline
\end{tabular}

Data were also screened for multivariate outliers using a z-scores criterion, and as Osborne (2014) suggests, standardized z-scores greater than \pm 3.29 should be excluded. The minimum $z$-score was -2.80 and the maximum was 1.23 , and in this case, no outliers were identified. Data were also checked for univariate normality distribution assumption, and despite conducting relevant transformations of variables, most variables were not normally distributed and had kurtosis greater than +1.00 . However, the assumption of normality, which is susceptible to a larger sample size (Field, 2009), was accepted because these variables were within an acceptable \pm 3 range (Kline, 2010). Multivariate normality was assessed using Analysis of Moment Structures (AMOS), and results showed acceptable normality. While the linearity and homoscedasticity assumptions were violated in this study, according to Tabachnick and Fidell (2007), it was still possible to proceed with the statistical analysis. Finally, collinearity was tested using the correlation matrix, and multicollinearity was measured by tolerance and the variance inflation indicators (Tabachnick \& Fidell, 2007).

Table 2: Component Correlation Matrix

\begin{tabular}{|l|c|c|c|}
\hline \multicolumn{1}{|c|}{ Component } & $\mathbf{1}$ & $\mathbf{2}$ & $\mathbf{3}$ \\
\hline Teaching presence & 1 & 0.74 & .67 \\
\hline Social Presence & 0.74 & 1 & .78 \\
\hline Cognitive Presence & 0.67 & 0.78 & 1 \\
\hline \multicolumn{3}{|l|}{} \\
Note: Extraction Method: Principal Component Analysis. \\
Rotation Method: Promax with Kaiser Normalization.
\end{tabular}

Table (2) shows that all correlations among independent variables are within the acceptable range $(\leq .90)$. Value of tolerance was greater than .10 , cutoff, 0.1 , and variance inflation factor (VIF) was greater than 10 . Therefore, no multicollinearity issues were detected. The Cronbach's Alpha indicated an excellent internal consistency reliability coefficient for all presences; Cronbach a.98 for the teaching presence, Cronbach a.95 for the social presence, and Cronbach a.97 for the cognitive presence. 


\section{Findings}

\subsection{Factor analysis}

To answer question one, principal component analysis with Promax rotation was used to extract the three factors representing the 34-items COI survey. As an oblique rotation method, Promax assumes that correlation exists between and among components (Hair, Black, Babin \& Anderson, 2019; Tabachnick \& Fidell, 2007). The aim was to examine the factorability of the $34 \mathrm{COI}$ items into the three components and assess the strength of correlation among these. Kaiser Normalization was applied and factors loading greater than 0.4 have been extracted. The Kaiser-Meyer-Olkin measure of sampling adequacy was 0.98, above the commonly recommended value of .70, and Bartlett's test of sphericity was significant $\left(\chi^{2}=32016.59\right)$, the $p$-value was $(.000<)$.

These findings indicate that there is sufficient significant correlation in the data for factor analysis. Primary factor loading of $\geq 0.4$ was achieved, and there were no cross-loadings of the factors. Table (3) shows that all components loaded heavily onto the appropriate factors; 13 indicators loaded onto teaching presence, 9 indicators loaded onto social presence, and 12 indicators also loaded onto cognitive presence. This suggests that the three-factor solution provided clean factor loadings. The Eigenvalues indicated that the three factors representing $\mathrm{TP}=65.93 \%, \mathrm{SP}=7.14 \%$, and $\mathrm{CP}=3.51 \%$ of variance accounted for the relevant variables and all factors accounted for 76.51 of the variances. The correlations between the three factors and the relevant variables confirm the hypothesized correlations between the three presences. These were 0.74 between cognitive presence and teaching presence, 0.67 between social presence and teaching presence, and .78 between social presence and cognitive presence. The Eigenvalues in the Scree Plot (Figure. 2) indicate that the three-factor solution would describe the data well.

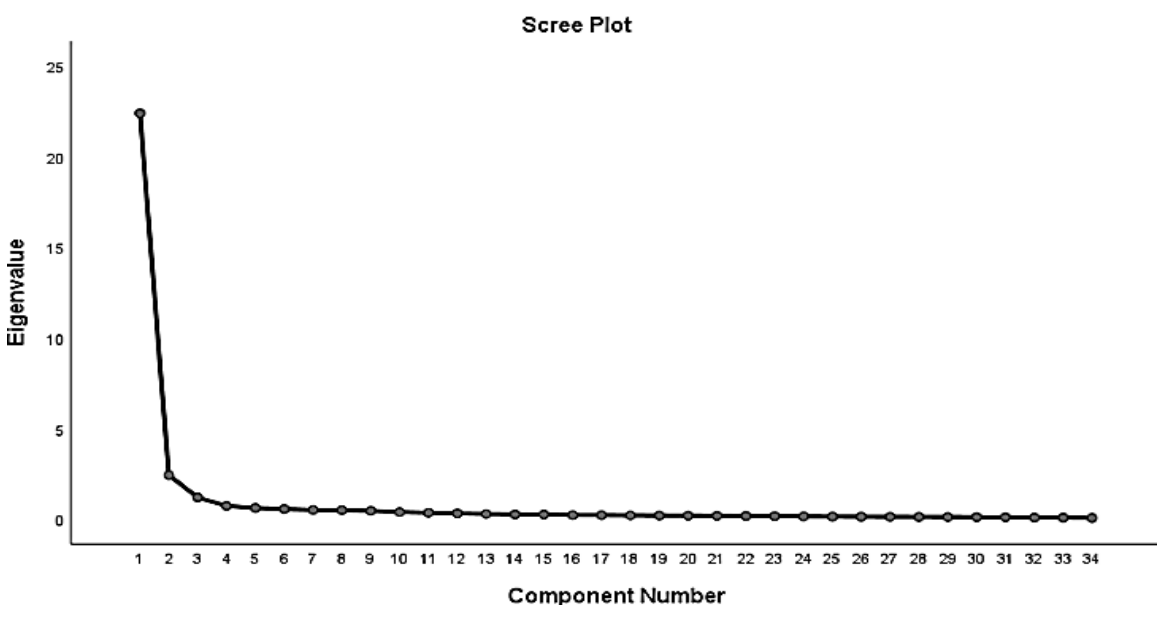

Figure 2: Scree plot of the eigenvalues 
Table 3: Factor loadings of the COI Framework

\begin{tabular}{|c|c|c|c|}
\hline Components & TP & $\mathbf{C P}$ & SP \\
\hline 2. The instructor clearly communicated important course goals. & 0.822 & & \\
\hline $\begin{array}{l}\text { 6. The instructor was helpful in guiding the class towards understanding } \\
\text { course topics in a way that helped me clarify my thinking. }\end{array}$ & 0.80 & & \\
\hline 1. The instructor clearly communicated important course topics. & 0.79 & & \\
\hline $\begin{array}{l}\text { 3. The instructor provided clear instructions on how to participate in course } \\
\text { learning activities. }\end{array}$ & 0.79 & & \\
\hline $\begin{array}{l}\text { 9. The instructor encouraged course participants to explore new concepts in } \\
\text { this course. }\end{array}$ & 0.78 & & \\
\hline $\begin{array}{l}\text { 5. The instructor was helpful in identifying areas of agreement and } \\
\text { disagreement on course topics that helped me to learn." }\end{array}$ & 0.78 & & \\
\hline $\begin{array}{l}\text { 8. The instructor helped keep the course participants on task in a way that } \\
\text { helped me to learn. }\end{array}$ & 0.78 & & \\
\hline $\begin{array}{l}\text { 4. The instructor clearly communicated important due dates/time frames for } \\
\text { learning activities. }\end{array}$ & 0.75 & & \\
\hline $\begin{array}{l}\text { 7. The instructor helped to keep course participants engaged and } \\
\text { participating in productive dialogue. }\end{array}$ & 0.74 & & \\
\hline $\begin{array}{l}\text { 10. Instructor actions reinforced the development of a sense of community } \\
\text { among course participants. }\end{array}$ & 0.74 & & \\
\hline $\begin{array}{l}\text { 11. The instructor helped to focus discussion on relevant issues in a way that } \\
\text { helped me to learn. }\end{array}$ & 0.74 & & \\
\hline 13. The instructor provided feedback in a timely fashion. & 0.71 & & \\
\hline $\begin{array}{l}\text { 12. The instructor provided feedback that helped me understand my } \\
\text { strengths and weaknesses relative to the course's goals and objectives. }\end{array}$ & & 0.42 & \\
\hline $\begin{array}{l}\text { 33. I have developed solutions to course problems that can be applied in } \\
\text { practice. }\end{array}$ & & 0.76 & \\
\hline 32. I can describe ways to test and apply the knowledge created in this course. & & 0.75 & \\
\hline 25. I felt motivated to explore content related questions. & & 0.75 & \\
\hline 24. Course activities piqued my curiosity. & & 0.73 & \\
\hline $\begin{array}{l}\text { 34. I can apply the knowledge created in this course to my work or other non- } \\
\text { class related activities. }\end{array}$ & & 0.71 & \\
\hline 30. Learning activities helped me construct explanations/solutions. & & 0.71 & \\
\hline 23. Problems posed increased my interest in course issues. & & 0.72 & \\
\hline $\begin{array}{l}\text { 31. Reflection on course content and discussions helped me understand } \\
\text { fundamental concepts in this class. }\end{array}$ & & 0.68 & \\
\hline $\begin{array}{l}\text { 27. Brainstorming and finding relevant information helped me resolve } \\
\text { content related questions. }\end{array}$ & & 0.68 & \\
\hline $\begin{array}{l}\text { 26. I utilized a variety of information sources to explore problems posed in } \\
\text { this course. }\end{array}$ & & 0.65 & \\
\hline $\begin{array}{l}\text { 29. Combining new information helped me answer questions raised in course } \\
\text { activities. }\end{array}$ & & 0.65 & \\
\hline $\begin{array}{l}\text { 28. Online discussions were valuable in helping me appreciate different } \\
\text { perspectives. }\end{array}$ & & 0.61 & \\
\hline 19. I felt comfortable interacting with other course participants. & & & 0.78 \\
\hline 17. I felt comfortable conversing through the online medium. & & & 0.77 \\
\hline 18. I felt comfortable participating in the course discussions. & & & 0.76 \\
\hline 22. Online discussions help me to develop a sense of collaboration. & & & 0.72 \\
\hline $\begin{array}{l}\text { 16. Online or web-based communication is an excellent medium for social } \\
\text { interaction. }\end{array}$ & & & 0.69 \\
\hline $\begin{array}{l}\text { 20. I felt comfortable disagreeing with other course participants while still } \\
\text { maintaining a sense of trust. }\end{array}$ & & & 0.67 \\
\hline 15. I was able to form distinct impressions of some course participants. & & & 0.66 \\
\hline $\begin{array}{l}\text { 21. I felt that my point of view was acknowledged by other course } \\
\text { participants. }\end{array}$ & & & 0.66 \\
\hline $\begin{array}{l}\text { 14. Getting to know other course participants gave me a sense of belonging in } \\
\text { the course. }\end{array}$ & & & 0.62 \\
\hline
\end{tabular}




\subsection{Structural equation model}

To answer questions two and three, the COI model was tested using the structural equation model (SEM). SEM is a data analysis technique used to create path analysis to assess the relationships among observed and latent variables (Kline, 2010). It is used in this research to examine the hypothesized causal relationships among the 34-COI items (observed variables) and how these define the three presences (latent variables) of the COI model. The direct and indirect effects (Table 4) of gender and academic program on the three presences are also examined. AMOS graphical interface (SPSS Inc.) version 18.0 was used to visualize SEM.

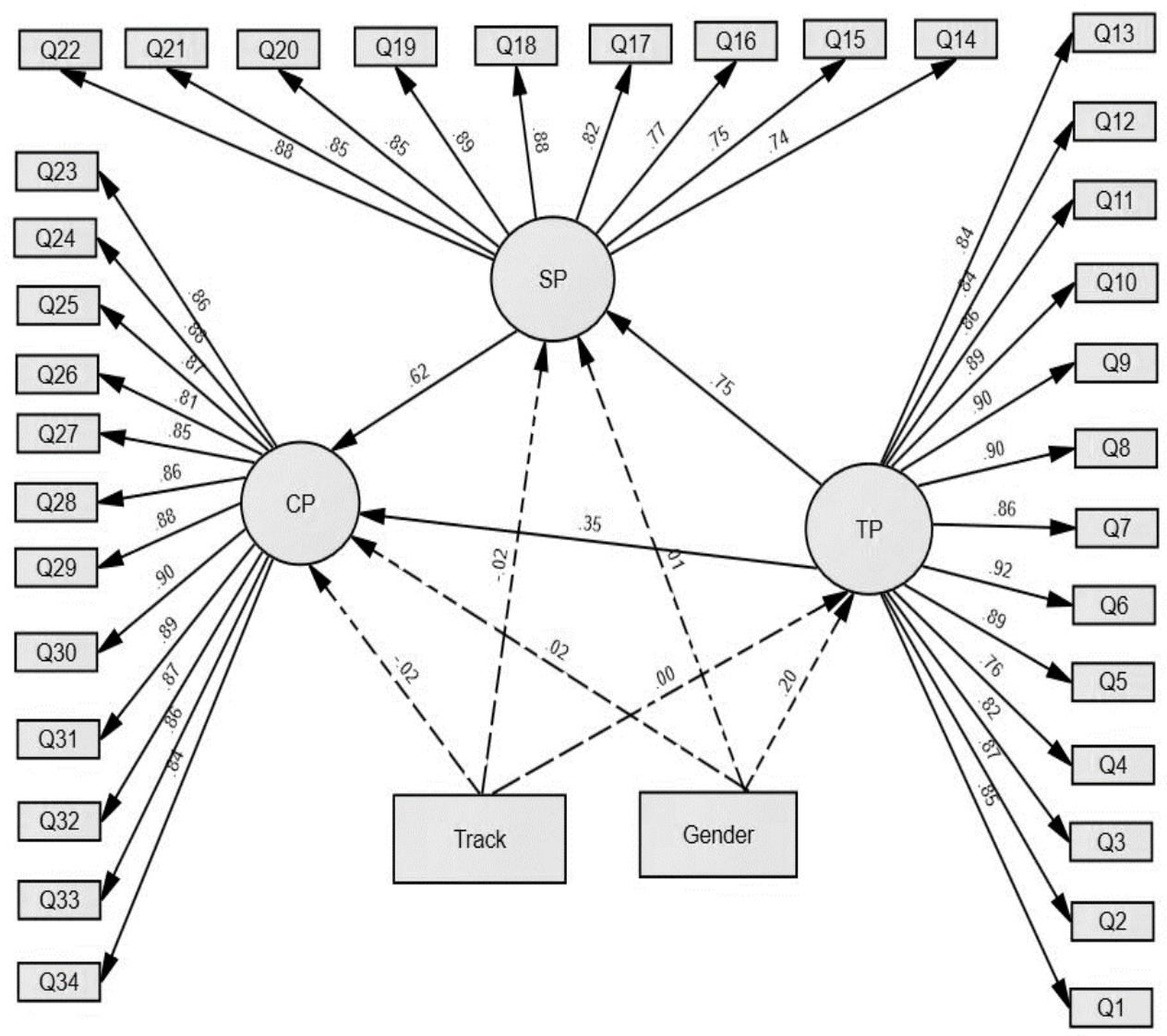

Figure 3: Model of the standardized relationships among teaching, cognitive and social presences

The covariance structure analysis was achieved by comparing the hypothesized and observed covariance matrices, and hypothesized structural relationships were confirmed. Maximum likelihood estimation was used to assess the overall fit of the model (Bollen \& Noble, 2011). The Fit indices produced were (ChiSquare $=2814.80, \mathrm{df}=577$, GFI 0.82, CFI 0.93, SPMR 0.04, and RMSEA .073, TLI=0.92 and $\mathrm{P}$ of close fit 0.00 ) which suggested a good model fit consistent with the sample size (Hu \& Bentler, 1999; Kline, 2010). The model (Figure. 3) shows that students' perception of teaching presence significantly predicts perceptions of cognitive presence, and the hypothesized mediating effect of social presence was confirmed as significant as well. 
Table 4: Standardized and unstandardized path coefficients and total effects

\begin{tabular}{|l|c|c|c|c|c|}
\hline \multirow{2}{*}{ Path } & \multicolumn{2}{|c|}{ Unstandardized coefficient } & \multicolumn{2}{|c|}{ standardized coefficient } & \multicolumn{1}{|l|}{ value } \\
\cline { 2 - 6 } & Direct Effect & Total Effect & Direct Effect & $\begin{array}{c}\text { Total } \\
\text { Effect }\end{array}$ & \\
\hline Gender to TP & 0.39 & 0.39 & 0.20 & 0.20 & $* *$ \\
\hline Track to TP & -0.00 & -0.00 & -0.00 & -0.00 & 0.98 \\
\hline Gender to SP & 0.03 & 0.34 & 0.02 & 0.17 & 0.58 \\
\hline TP to SP & 0.79 & 0.79 & 0.75 & 0.75 & $* *$ \\
\hline Track to SP & -0.03 & -0.04 & -0.02 & -0.02 & 0.56 \\
\hline SP to CP & 0.60 & 0.60 & 0.62 & 0.62 & $* *$ \\
\hline Track to CP & -0.03 & -0.06 & -0.02 & -0.02 & 0.38 \\
\hline TP to CP & 0.36 & 0.83 & 0.35 & 0.82 & $* *$ \\
\hline Gender to CP & 0.04 & 0.39 & 0.02 & 0.20 & 0.21 \\
\hline
\end{tabular}

\subsection{CHAID analysis}

To answer question four, Chi-square automatic interaction detection (CHAID) was used as a multivariate analysis to model the hypothesized relationship among the COI three presences where TP and SP can explain the development of CP. CHAID algorithm is a non-parametric method of analyzing structural relationships among categorical, nominal, or ordinal response and predictor variables (Field, 1977). It has many advantages as it does not require normality, homogeneity, and linearity assumptions of the data to be met (Magidson \& Vermunt, 2005). It produces a decision-tree that visualizes the relationship between the categorical dependent variable and independent variables. The three factors are considered nominal variables, while the 34-items are ordinal variables. $\mathrm{CP}$ is the dependent variable, whereas TP and $\mathrm{CP}$ are the independent variables. Unlike the results drawn from the structural equation model, which categorizes the coherent items of cognitive presence, CHAID analysis visualizes the most significant items in social and teaching presences that greatly influence cognitive development (Shea \& Bidjerano, 2009. Through this, it was possible to detect the highest and lowest level items from the teaching and social presence that segments students' perceptions of higher and lower cognitive presence.

The results of the CHAID procedure (Figure. 4) indicate that the model contains 11 nodes within three levels of the tree depth. The most significant independent variable is item 22 of the social presence indicator (online discussion helps me to develop a sense of collaboration). This indicates that it is the variable that is most strongly associated with $\mathrm{CP}$, and therefore, it has the largest potential for sorting students into cognitively present learners. It splits the root node $(\mathrm{CP})$ into five groups (nodes1-5), and the majority of participants $(n=312)$ belong to node 4 (neutral and agree). Indicator 11 of the TP indicator (The instructor helped to focus discussion on relevant issues in a way that helped me to learn) has the most influence on CP. The respondents were split into two groups; 262 who are neutral in predicting the highest impact (3.93) and 50 neutral who were predicting the lowest impact on $\mathrm{CP}$. On deciding whether to retain this finding, it is important to consider current debates on the issue of neutrality or mid-point position in attitudinal or survey research. It is not clear whether this neutral position is genuine, and therefore this ambiguity may reduce research reliability and validity 
(Sturgis, Roberts \& Smith, 2014). As they suggest, "this ambiguity can only be resolved by the administration of follow-up probes" (p.35), and this may be pursued in future studies. Further analysis of this node resulted in indicator 6 of TP (The instructor was helpful in guiding the class towards understanding course topics in a way that helped me clarify my thinking) as the third most statistically significant indicator predicting CP. It splits respondents into two groups. The highest number was 207respondents who reported that item 6 predicts $28.1 \%$ impact on the cognitive presence.

Indicator 10 of TP factor (Instructor actions reinforced the development of a sense of community among course participants) has the second most significant impact on cognitive presence as 207 respondents agree that item 10 has 28.1 impact on CP. 146 of these respondents were assigned the highest position in predicting this association at $19.6 \%$, while 61 respondents reported that indicator 10 predicted $8.3 \%$ of the impact on cognitive presence.

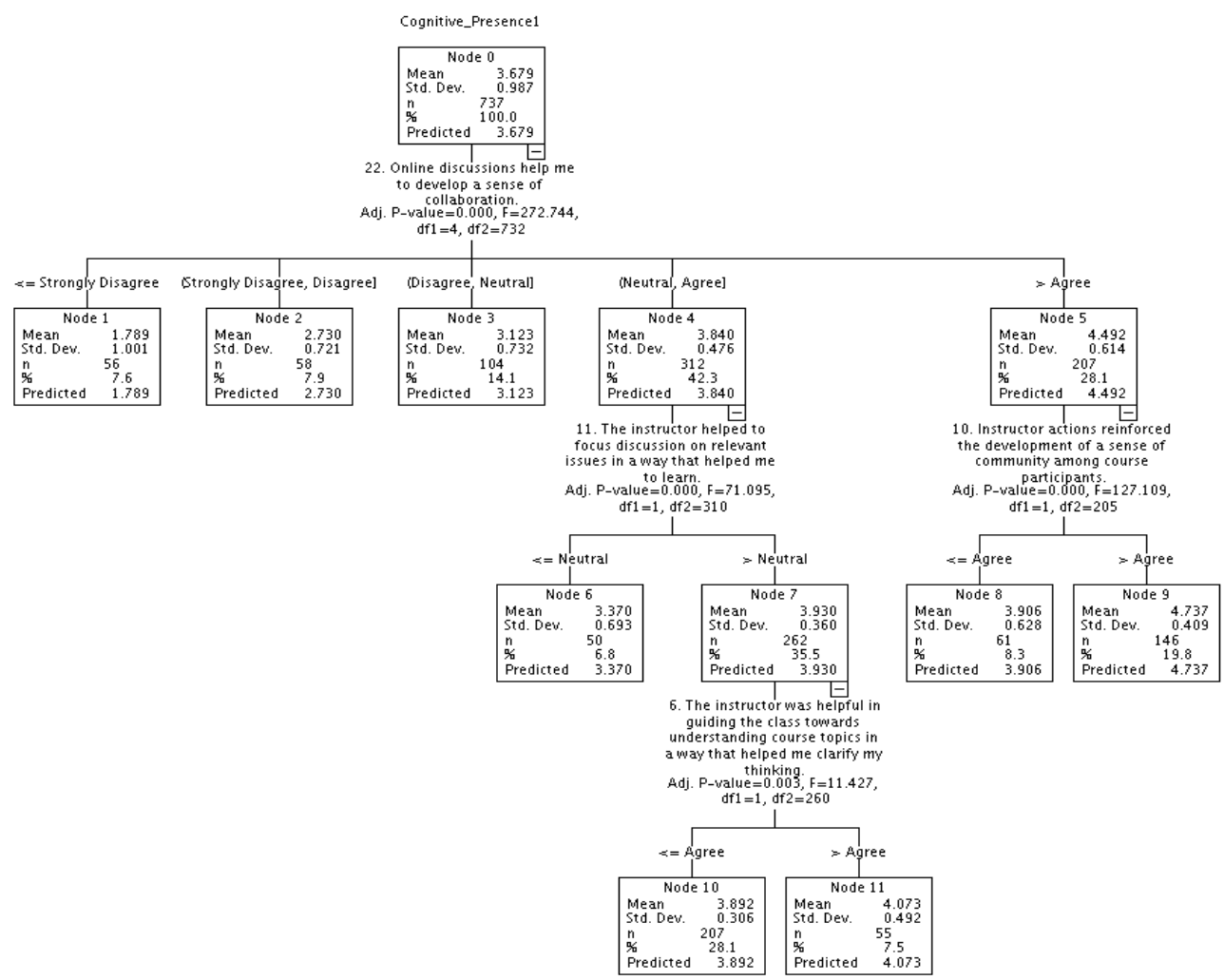

Figure 4: CHAID analysis of cognitive presence scores

\section{Discussion}

This paper aimed to examine EFL learners' perceptions about the causal relationships among the three COI presences and the impact of gender and academic program on the realization of these presences. First, the internal consistency reliability of the adopted COI instrument was high, as also suggested in some seminal work in this field (Alaulamie, 2014; Arbaugh et al., 2008; Garrison et al., 2010; Shea \& Bidjerano, 2009). The factor analysis findings indicated that $76.51 \%$ of the variance in students' perceptions was explained by the three 
presences of the COI framework. This means that three presence heavily existed in the EFL online course due to the dynamic interplay among these (Garrison et al., 2010). It seems that the course design supports and encourages the formation of a community of inquiry to develop communicative language skills among learners, as also suggested in similar studies (Goda \& Yamada, 2013; Ke, 2010; Lee, 2014).

The findings of the structural equation modelling confirm the hypothesized causal relationships among the three presences of the COI framework. TP was perceived as the most fundamental element in shaping learners' meaningful and successful educational experience. It was perceived to directly predict $\mathrm{SP}$ and $\mathrm{CP}$ and SP predicted CP. These findings are consistent with research conducted on COI both in language acquisition and mainstream education research. Garrison et al. (2010) reported a moderate fitting model in which TP was the core factor in establishing and maintaining an effective community of inquiry in an online learning environment, and SP performed a mediating role to help learners actively construct knowledge. Shea and Bidjerano (2009) also reported a good fitting model that confirms the core function of teaching presence in cultivating a thriving community of inquiry. TP and SP directly predicted $\mathrm{CP}$, and SP was perceived to predict $\mathrm{CP}$ indirectly. The causal relationships confirmed in this research study highlight the critical roles teaching and social presences play in designing and cultivating inquiry engendered learning environments that stimulate higher order thinking and critical discourse (Kozan \& Richardson, 2014a; Garrison et al., 2010; Garrison, 2017). In such environments, learners can construct knowledge through scaffolding, reflection, collaboration, and dialogue. In addition, findings from the structural equation model in this research study confirm findings reported in the literature (Garrison et al., 2010; Shea \& Bidjerano, 2009 ) that the cultivation of CP can be predicted by TP and SP and that SP plays a mediating role to enhance students' engagement in inquiry enriched environments. CHAID analysis results in this study also confirm that SP and TP account for higher levels of CP. Specifically, SP indicator 22 and TP indicators 11 and 10 correlate with variance in learners' $\mathrm{CP}$. This finding is consolidated by Shea and Bidjerano (2009), who reported that high CP was attributed to SP. However, while in this study, the online discussion helped learners develop higher levels of cognitive presence, for She and Bidjerano (2009), it was the level of comfort that enabled higher levels of cognitive engagement. In this study, the most significant impact on cognitive presence was attributed to online discussion. This finding suggests that teachers utilized synchronous chat functions and discussion boards in Blackboard to enhance students' collaboration and discussion to attain higher cognitive presence levels. The lower levels of CP can be predicted by lower levels of online discussions and lack of a sense of collaboration. This result supports the idea that attention should be paid to emotional aspects of learning, such as the feeling of comfort in participation as suggested by shea and Bidjerano (2009), and engaging students in online collaborative discussion activities. The impact of TP in directing SP and $\mathrm{CP}$ reported in this research is in contrast with the findings of Lee (2014), who indicated minimal teacher intervention, and as a result, only SP predicted $\mathrm{CP}$. This finding confirms the COI framework principles, emphasizing that learning is a collaborative process of all the three presences (Kozan \& 
Richardson, 2014b). That is, teachers in this study could use the chatbox to design, facilitate, and direct instruction (TP). Students then can address triggering events, explore, integrate, and resolve problem questions (CP). This process can be facilitated through open communication, affective expression, and group cohesion (SP). These results confirm the findings of previous research (Asoodar et al., 2014; Goda \& Yamada, 2013) regarding the effect of TP and SP in directing synchronous (and asynchronous) communication (chats, emails, and forum discussions) to the attainment of $\mathrm{CP}$. The communicative competence, oral proficiency, and grammatical awareness were reported in the literature to indicate SP and CP enhanced through TP in online learning environments (Goda \& Yamada, 2013; Olesova et al., 2011). While investigating linguistic skills is beyond the scope of this study, it can be argued that the teaching presence orientated learners to engage in meaningful collaborative and communicative activities. The sense of collaboration demonstrated by using the synchronous chatbox both by teachers and students during online classes seem to enhance learners' communicative competence. Indicator 10 of TP seems to motivate teachers to utilize synchronous chatbox or asynchronous discussion boards to encourage learners to socialize, communicate, and provide and receive spontaneous feedback. Similar findings were reported by Olesova et al. (2011), who indicated that teachers' audio feedback enhanced learners' cognitive presence. Confirming this finding, Goda and Yamada (2013) demonstrated a significant relationship between SP and discussion comment number. Moreover, students' contributions to the discussion were correlated with design and organization in TP, suggesting that student contribution to discussions in an online COI is enhanced by TP.

The findings of this research also indicate that gender predicts perceptions of TP in a community of inquiry in online learning environments. Shea and Bidjerano (2009) confirmed that gender significantly correlated with TP. The program of study (general or academic English track) in this research did not, however, predict any of each of the presences. This outcome is contrary to previous studies (e.g., Garrison et al., 2010), which have suggested that the program of study significantly predicted CP. Contradictory results were also reported by Shea and Bidjerano (2009), who found that the academic program of study predicted teaching presence. On reflection, it is reasonable to suggest that gender variance in the context of this research study can be assigned to the social richness women experience in online learning environments (Rovai \& Baker, 2005). As Al lHassan and Shukri (2017, p. 200) confirm, Saudi female students' satisfaction with online learning is assigned to "appropriateness, variety of activities in contents and forms" and teachers' roles in motivating students in online environments. Since the tutors for female students in the context of this study are females, it is reasonable to suggest that students' satisfaction is brought about by "some aspects of academic practice" including "relations with tutors and tutorial practice." (Richardson and Long, 2003, p.240). Future research is called for to explore this relationship. Finally, the neutral effect of the program of study can be assigned to the shared goal of learning English as a foreign language to attain the required language proficiency irrespective of the major of study. 


\section{Limitations}

A potential limitation of the research reported in this study is the relatively small sample size. An implication of this is the Chi-square test, which is susceptible to the limitations of the correlational design of the study, and therefore the findings of the study should be explained in light of these limitations. Additionally, owing to the design of the study, it was not possible to identify what tools other than synchronous chatbox and discussion boards have enhanced the social presence. Moreover, in the absence of collaborative activities such as shared project work, it was difficult to identify what language skills were developed in an online learning environment due to teaching and social presence. More qualitative research is therefore needed to explore the effect of the COI framework on language skills development. Despite these weaknesses, the study provides a strong case to support using the COI framework as a reliable instrument for EFL researchers and practitioners in Saudi Arabia and elsewhere to assess perceptions and experiences of learning English online.

\section{Conclusion}

The findings reported in this study confirm the established causal relationships among the COI presences and highlight that TP is a crucial indicator in the cultivation of a community of inquiry in online learning settings. It also confirms that the COI framework is a useful tool to uncover the dynamic relationships among TP, SP, and CP in different sociocultural settings, such as those reported in this study. It also suggests that the COI framework is valuable in providing insights into the existence of the three presences in online learning environments as indicators of the attainment of quality educational experience, especially at times of crises such as Covid-19. In addition, the results reported in this study suggest that the COI framework proves valuable as a tool for online language education. It also provides significant insights into how the design of online language courses can enhance language learners' SP and CP. The dynamic relationships among the three presences uncovered in this study suggest that learners' positive experiences can be predicted by the learning affordances that enable learners to develop communicative competence and oral proficiency and leads to an overall positive linguistic achievement (Goda \& Yamada, 2013; Olesova et al., 2011). The implication for practice is that EFL teachers play an essential role in enhancing class interactions to develop learners' communicative competence and promote situated language learning (Bax, 2003; Block, 2003).

\section{References}

Adamus, T., Kerres, M., Getto, B., \& Engelhardt, N. (2009, March 5-9). Gender and etutoring: A concept for gender sensitive e-tutor training programs. Paper presented at the 5th European symposium on gender and ICT digital cultures: ParticipationEmpowerment-Diversity, 2009, University of Bremen, Germany (pp. 5-7). Retrieved from http://www.informatik.unibremen.de/soteg/gict2009/proceedings/GICT2009_Adamus.pdf

Akyol, Z., \& Garrison, D. (2008). The development of a community of inquiry over time in an online course: understanding the progression and integration of social, cognitive, and teaching presence. Journal of Asynchronous Learning Networks, 12(34), 3-22. http:/ / dx.doi.org/10.24059/olj.v12i3.66 
Akyol, Z., \& Garrison, D. (2011). Assessing metacognition in an online community of inquiry. The Internet and Higher Education, 14(3), 183-190. https://doi.org/10.1016/j.iheduc.2011.01.005

Al lHassan, S., \& Shukri, N. (2017). The Effect of Blended Learning in Enhancing Female Students' Satisfaction in the Saudi Context. English Language Teaching, 10(6), 190203.

Al Lily, A. (2011). Online and under veil: Technology-facilitated communication and female experience within academia. Technology in Society, 33(1-2), 119-127. https:// doi.org/10.1016/j.techsoc.2011.03.005

Alaulamie, L. A. (2014). Teaching presence, social presence, and cognitive presence as predictors of students' satisfaction in an online program at a Saudi University (Doctoral dissertation, Ohio University, Ohio, USA). Retrieved from https://etd.ohiolink.edu/apexprod/rws_etd/send_file/send?accession=ohiou1 395341753\&disposition=attachment

Alavi, S., \& Taghizadeh, M. (2013). Cognitive presence in a virtual learning community: An EFL Case. International Journal of E-learning \& Distance Education, 27(1). Retrieved from http://www.ijede.ca/index.php/jde/article/view/818

Arbaugh, J., Cleveland-Innes, M., Diaz, S. R., Garrison, D. R., Ice, P., Richardson, J. C., \& Swan, K. P. (2008). Developing a community of inquiry instrument: Testing a measure of the community of inquiry framework using a multi-institutional sample. The internet and higher education, 11(3-4), 133-136. https://doi.org/10.1016/j.iheduc.2008.06.003

Archibald, D. (2010). Fostering the development of cognitive presence: Initial findings using the community of inquiry survey instrument. Internet $\mathcal{E}$ Higher Education, 13(1-2), 73-74. https:// doi.org/10.1016/j.iheduc.2009.10.001

Asoodar, M., Atai, M. R., Vaezi, S., \& Marandi, S. S. (2014). Examining effectiveness of communities of practice in online English for academic purposes (EAP) assessment in virtual classes. Computers $\mathcal{E}$ Education., 70, 291-300. https://doi.org/10.1016/j.iheduc.2009.10.001.

Bax, S. (2003). CALL-past, present and future. System, 31(1), 13-28. https://doi.org/10.1016/S0346-251X(02)00071-4

Blake, C. (2009). Potential of text-based internet chats for improving oral fluency in a second language. The Modern Language Journal, 93(2), 227-240. https://doi.org/10.1111/j.1540-4781.2009.00858.x

Block, D. (2003). The Social Turn in Second Language Acquisition. Georgetown University Press, NW, Washington, DC.

Bollen, K. \& Noble, M. (2011). Structural equation models and the quantification of behavior. In D. Pfaff (Ed.), Quantification of Behavior. Conference Proceedings of the Arthur M. Sackler Colloquium of the National Academy of Sciences (1563915646). The Rockefeller University, New York. https://doi.org/10.1073/pnas.1010661108.

Field, A. (2013). Discovering statistics using IBM SPSS statistics (4th ed.). London, England: sage.

Fotos, S., \& Browne, C. (Eds.). (2013). New perspectives on CALL for second language classrooms. London, England: Routledge. https://doi.org/10.4324/9781410610775

Fowler, F. (2009). Survey Research Methods (4th ed.). Newbury Park, CA: Sage https://doi.org/10.4135/9781452230184

Garrison, D. (2017). E-learning in the 21st century: A community of inquiry framework for research and practice (3rd ed.). London, England: Routledge. 
Garrison, D., \& Arbaugh, J. (2007). Researching the community of inquiry framework: Review, issues, and future directions. The Internet and higher education, 10(3), 157172. https://doi.org/10.4324/9781315667263

Garrison, D., \& Cleveland-Innes, M. (2005). Facilitating cognitive presence in online learning: Interaction is not enough. The American journal of distance education, 19(3), 133-148. https://doi.org/10.1207/s15389286ajde1903_2

Garrison, D., Cleveland-Innes, M., \& Fung, T. (2010). Exploring causal relationships among teaching, cognitive and social presence: Student perceptions of the community of inquiry framework. The internet and higher education, 13(1-2), 31-36. https://doi.org/10.1016/j.iheduc.2009.10.002

Garrison, D., Anderson, T., \& Archer, W (2000). Critical inquiry in a text-based environment: Computer conferencing in higher education. The Internet and Higher Education, 2(2-3): 87-105. https:// doi.org/10.1016/s1096-7516(00)00016-6

Goda, Y., \& Yamada, M. (2013). Application of CoI to design CSCL for EFL online asynchronous discussion. In Z. Akyol \& D. Garrison (Eds.), Educational Communities of Inquiry: Theoretical Framework, Research and Practice (pp. 295-316). PA: IGI Global. https:/ / doi.org/10.4018/978-1-4666-2110-7.ch014

Hair, J. F., Black, W. C., Babin, B. J., \& Anderson, R. E. (2019). Multivariate data analysis (7th ed). NJ: Pearson Prentice Hall

Henry, A. (2019). Online media creation and L2 motivation: A socially situated perspective. TESOL Quarterly, 53(2), 372-404. https://doi.org/10.1002/tesq.485

Hu, L. T., \& Bentler, P. M. (1999). Cutoff criteria for fit indexes in covariance structure analysis: Conventional criteria versus new alternatives. Structural equation $\begin{array}{lllll}\text { modelling: } \quad \text { multidisciplinary journal, } & 6(1), & 1-55 .\end{array}$ https://doi.org/10.1080/10705519909540118

Ke, F. (2010). Examining online teaching, cognitive, and social presence for adult students. $\begin{array}{llll}\text { Computers } \& \text { Education, } & \text { 508-820. }\end{array}$ https://doi.org/10.1016/j.compedu.2010.03.013

Kline, R. B. (2010). Principles and practice of structural equation Modelling (3rd ed.). NY: Guilford Press.

Kozan, K., \& Richardson, J. C. (2014a). Interrelationships between and among social, teaching, and cognitive presence. The Internet and Higher Education, 21, 68-73. https://doi.org/10.1016/j.iheduc.2013.10.007

Kozan, K., \& Richardson, J. (2014b). New exploratory and confirmatory factor analysis insights into the community of inquiry survey. The Internet and Higher Education, 23, 39-47. https://doi.org/10.1016/j.iheduc.2014.06.002

Lambert, J. L., \& Fisher, J. L. (2013). Community of inquiry framework: Establishing community in an online course. Journal of Interactive Online Learning, 12(1), 1-16. https://doi.org/10.1080/08841233.2019.1642976

Lamy, M., \& Hampel, R. (2007). Online communication in language learning and teaching. NY: Palgrave Macmillan.

Lantolf, J. P. (2003). Intrapersonal communication and internalization in the second language classroom. In A. Kozulin, B. Gindis, V. S. Ageyev, \& S. M. Miller (Eds.). Vygotsky's educational theory in cultural context, (pp. 349-370). Cambridge, England: Cambridge University Press. https://doi.org/10.1017/cbo9780511840975.018

Lee, S. M. (2014). The relationships between higher order thinking skills, cognitive density, and social presence in online learning. The Internet and Higher Education, 21, 41-52. https:// doi.org/10.1016/j.iheduc.2013.12.002

Macaro, E., Handley, Z., \& Walter, C. (2012). A systematic review of CALL in English as a second language: Focus on primary and secondary education. Language Teaching, 45, 1-43. https://doi.org/10.1017/s0261444811000395 
Magidson, J., \& Vermunt, J. K. (2005). An extension of the CHAID tree-based segmentation algorithm to multiple dependent variables. In C. Weihs \& W. Gaul (Eds.). Classification - The Ubiquitous Challenge. Proceedings of the 28th annual conference of the Gesellschaft für Klassifikation e.V., (240-247). University of Dortmund, Berlin, Germany: Springer-Verlag. https://doi.org/10.1007/3-540-28084-7_18

Müller, T. (2008). Persistence of Women in Online Degree-Completion Programs. The International Review of Research in Open and Distributed Learning, 9(2). https:// doi.org/10.19173/irrodl.v9i2.455

Olesova, L., Richardson, J., Weasenforth, D., \& Meloni, C. (2011). Using asynchronous instructional audio feedback in online environments: A mixed methods study. MERLOT Journal of Online Learning and Teaching, 7(1), 30-42.

Osborne, J. W., \& Overbay, A. (2004). The power of outliers (and why researchers should always check for them). Practical Assessment, Research, and Evaluation, 9(1), 6. https://doi.org/10.7275/qf69-7k43.

Pederson, R. (2012). Situated learning: Rethinking a ubiquitous theory. Journal of Asia TEFL, 9(2), 123-148.

Pinto-Llorente, A. M., Sánchez-Gómez, M. C., García-Peñalvo, F. J., \& Casillas-Martín, S. (2017). Students' perceptions and attitudes towards asynchronous technological tools in blended-learning training to improve grammatical competence in English as a second language. Computers in Human Behavior, 72, 632-643. https://doi.org/10.1016/j.chb.2016.05.071

Richardson, J. T., \& Long, G. L. (2003). Academic engagement and perceptions of quality in distance education. Open Learning, 18(3), 223-244. https://doi.org/10.1080/0268051032000131008

Rovai, A., \& Baker, J. (2005). Gender differences in online learning: Sense of community, perceived learning, and interpersonal interactions. The Quarterly Review of Distance Education, 6(1), 31-44.

Shea, P., \& Bidjerano, T. (2009). Community of inquiry as a theoretical framework to foster "epistemic engagement" and "cognitive presence" in online education. Computers $\mathcal{E}$ Education, 52(3), 543-553. https:// doi.org/10.1016/j.compedu.2008.10.007

Shea, P., \& Bidjerano, T. (2010). Learning presence: Towards a theory of self-efficacy, selfregulation, and the development of a communities of inquiry in online and blended learning environments. Computers \& Education, 55(4), 1721-1731. https:// doi.org/10.1016/j.compedu.2010.07.017

Sturgis, P., Roberts, C., \& Smith, P. (2014). Middle Alternatives Revisited: How the neither/nor Response Acts as a Way of Saying "I Don't Know"? Sociological Methods \& Research, 43(1), 15-38. https:/ / doi.org/10.1177/0049124112452527

Tabachnick, B. G., \& Fidell, L. S. (2007). Using multivariate statistics. Boston, MA: Pearson Education.

Wang, W., \& Zhan, J. (2020). The Relationship Between English Language Learner Characteristics and Online Self-Regulation: A Structural Equation Modelling Approach. Sustainability, 12(7), 3009. https://doi.org/10.3390/su12073009 


\section{Appendix 1. Community of Inquiry Survey Instrument (draft v14)}

\section{Teaching Presence}

\section{Design \& Organization}

1. The instructor clearly communicated important course topics.

2. The instructor clearly communicated important course goals.

3. The instructor provided clear instructions on how to participate in course learning activities.

4. The instructor clearly communicated important due dates/time frames for learning activities.

\section{Facilitation}

5. The instructor was helpful in identifying areas of agreement and disagreement on course topics that helped me to learn.

6. The instructor was helpful in guiding the class towards understanding course topics in a way that helped me clarify my thinking.

7. The instructor helped to keep course participants engaged and participating in productive dialogue.

8. The instructor helped keep the course participants on task in a way that helped me to learn.

9. The instructor encouraged course participants to explore new concepts in this course.

10. Instructor actions reinforced the development of a sense of community among course participants.

\section{Direct Instruction}

11. The instructor helped to focus discussion on relevant issues in a way that helped me to learn.

12. The instructor provided feedback that helped me understand my strengths and weaknesses relative to the course's goals and objectives.

13. The instructor provided feedback in a timely fashion.

\section{Social Presence}

\section{Affective expression}

14. Getting to know other course participants gave me a sense of belonging in the course.

15. I was able to form distinct impressions of some course participants.

16. Online or web-based communication is an excellent medium for social interaction. 
Open communication

17. I felt comfortable conversing through the online medium.

18. I felt comfortable participating in the course discussions.

19. I felt comfortable interacting with other course participants.

Group cohesion

20. I felt comfortable disagreeing with other course participants while still maintaining a sense of trust.

21. I felt that my point of view was acknowledged by other course participants.

22. Online discussions help me to develop a sense of collaboration.

\section{Cognitive Presence}

Triggering event

23. Problems posed increased my interest in course issues.

24. Course activities piqued my curiosity.

25. I felt motivated to explore content related questions.

Exploration

26. I utilized a variety of information sources to explore problems posed in this course.

27. Brainstorming and finding relevant information helped me resolve content related questions.

28. Online discussions were valuable in helping me appreciate different perspectives. Integration

29. Combining new information helped me answer questions raised in course activities.

30. Learning activities helped me construct explanations/solutions.

31. Reflection on course content and discussions helped me understand fundamental concepts in this class.

\section{Resolution}

32. I can describe ways to test and apply the knowledge created in this course.

33. I have developed solutions to course problems that can be applied in practice.

34. I can apply the knowledge created in this course to my work or other non-class related activities.

Source: (http://www.thecommunityofinquiry.org/CoISurveyDraft14b1.pdf) 